\section{Questión}

Periodismo / Comunicación ISSN 1669-6581
- Av. $44 \mathrm{~N}^{\circ} 676,1^{\circ}$ piso

CP 1900 - La Plata - Argentina

( www.perio.unlp.edu.ar/question

La comunicación en el aislamiento. Información, educación, entretenimiento y sexting en

contexto de pandemia

Leonardo Murolo

DOI: https://doi.org/10.24215/16696581e351

\title{
La comunicación en el aislamiento. Información, educación, entretenimiento y sexting en contexto de pandemia
}

\author{
Communication in isolation. Information, education, \\ entertainment and sexting in the context of a pandemic
}

\section{Leonardo Murolo}

Doctor en Comunicación (UNLP). Es profesor de grado y posgrado en la UNQ y en la FPyCS-

UNLP. Dirige la Licenciatura en Comunicación Social UNQ. Ha obtenido las becas de CONICET y ERASMUS MUNDUS. Dirige el proyecto de investigación "Tecnologías, política, cultura popular y masiva. Usos y narrativas de la comunicación en redes". Publica trabajos de investigación y de divulgación en temáticas relacionadas a los usos de las tecnologías, medios y audiovisual digital. Escribe sobre series y cultura popular en el diario Tiempo Argentino. 


\section{Resumen}

El aislamiento social preventivo y obligatorio dispuesto por el Poder Ejecutivo Nacional en marzo de 2020 implicó la reconfiguración de dinámicas cotidianas, entre ellas las prácticas de comunicación. El acatamiento a la directiva gubernamental de aislamiento fue alto. Desde allí hubo que aprender a construir una forma de transitarlo y por lo tanto es propicio advertir las características de este proceso. En el presente artículo se reflexiona sobre los usos de la comunicación y de manera puntual de las apropiaciones tecnológicas en este periodo. Recurriremos a fuentes periodísticas, las cuales ofician como testimonios sincrónicos de los acontecimientos en la coyuntura de la pandemia. Estudiar los medios nos acerca a comprender, en palabras de Silverstone, parte de la textura general de la experiencia que construimos en nuestras cotidianidades. Desde allí, esta sistematización funciona como impronta de época y fotografía de un momento histórico inédito en la contemporaneidad.

\section{Palabras Clave}

Aislamiento - Comunicación - Información

\section{Key Words}

Isolation - Communication - Information

\section{La comunicación en el aislamiento}

El acatamiento a la directiva gubernamental de aislamiento fue alto. Desde allí hubo que aprender a construir una forma de transitarlo y por lo tanto es propicio advertir las características de este proceso. Vamos a reflexionar sobre los usos de la comunicación y de manera puntual de las apropiaciones tecnológicas en este periodo. Recurriremos a fuentes periodísticas, las cuales ofician como testimonios sincrónicos de los acontecimientos en la coyuntura de la pandemia. Estudiar los medios nos acerca a comprender parte de la textura general de la experiencia que construimos en nuestras cotidianidades 
El 19 de marzo de 2020 el Poder Ejecutivo Nacional decretó el Aislamiento Social Preventivo Obligatorio a raíz de una pandemia de escala mundial causada por el virus covid-19'. Como situación inédita en la vida contemporánea, la ciudadanía debió acatar y regirse por las reglas de esta cuarentena. Con algunas salvedades como poder salir a comprar alimentos a comercios de cercanía, trabajar si se pertenece a personal esencial y asistir a personas que lo necesiten, el resto de las actividades quedaron suspendidas para preservar la salud de la población. Deberíamos remontarnos lejos en la historia moderna para encontrar una situación similar de aislamiento obligatorio. Sin embargo, a pesar de la poca habitualidad, el acatamiento de esta directiva gubernamental fue alto. Desde allí hubo que aprender a construir una forma de transitarlo y por lo tanto es propicio advertir las características de este proceso.

El aislamiento social preventivo y obligatorio de 2020 será objeto de estudio de las ciencias sociales en sus más diferentes dimensiones: economía, psicología, sociología, antropología. Incluso de manera sincrónica, los grandes intelectuales del mundo corrieron a exponer sus ideas en publicaciones urgentes. En nuestro caso nos ocupa la comunicación, una mirada que focaliza en las construcciones de significados, representaciones, estereotipos, imaginarios, en una relación con las disputas hegemónicas por estos sentidos y un terreno privilegiado para la construcción de identidades. En esa dirección podemos comenzar a reflexionar, muy cercanos al fenómeno en discusión, sobre los usos de la comunicación y de manera puntual de las apropiaciones tecnológicas en este periodo. Para este fin recurriremos a fuentes periodísticas, las cuales ofician como testimonios sincrónicos de los acontecimientos en la coyuntura de la pandemia. Estudiar los medios nos acerca a comprender parte de la textura general de la experiencia que construimos en nuestras cotidianidades (Silverstone, 2004).

Es interesante pensarnos en un momento histórico donde las tecnologías de la comunicación, sus usos y la conectividad son protagonistas de la información y el entretenimiento. Pertenecemos a culturas mediáticas y desde fragmentos de medios de comunicación le conferimos sentido a muchas de nuestras prácticas (Rincón, 2005; Jenkins, 2010). Desde allí en un contexto de aislamiento obligatorio, la mayor parte de la ciudadanía se informó en sus hogares gran parte del día a través de medios de comunicación. Los medios tradicionales como la televisión y la radio subieron su encendido, al tiempo que las redes sociales aumentaron su participación. 
En ese contexto, la comunicación política gubernamental tomó una forma recurrente: conferencias de prensa o anuncios grabados por parte del Presidente de la Nación, Alberto Fernández, como también su asidua visita como entrevistado en diferentes programas de televisión. Incluso concedió una entrevista por Instagram Live a un conocido músico internacional. La comunicación presidencial directa y con mirada a cámara supuso también una importante repercusión en redes sociales. Primero con memes y frases relacionadas a la trayectoria docente de Alberto Fernández, quien acompañó sus anuncios con imágenes a las que llamó "filminas", desde las cuales presentó datos y apeló al compromiso ciudadano. Asimismo, se dirigió a las infancias como "chicos, chicas, chiques", invocando su responsabilidad, al tiempo que los instó a enviarle dibujos por Twitter desde sus casas, cosa que sucedió en cantidad y que el propio presidente respondió con afecto, incluso compartiendo un video que los recopilaii. Además, las comunicaciones rutinarias por parte del Ministerio de Salud de la Nación supusieron una cita obligada cada día para conocer datos oficiales y el avance del trabajo ante la pandemia.

No obstante la claridad de la información oficial, las redes sociales no tardaron de entrar en escena para que algunos usuarios hicieran correr fake news. Informaciones erróneas sobre cómo diagnosticar el virus, y hasta audios de Whatsapp de supuestos médicos informando casos y acciones que resultaron ser falsas. La historia de la mentira no es la historia de un error, sino que cuando hablamos de fake news debemos hablar de mentiras intencionadas (Aparici y García Marín, 2019). Dada la abundancia de información sobre la pandemia y las prácticas preexistentes pero potenciadas alrededor de las noticias falsas, no se tardó en denominar "infodemia" a los casos puntuales de fake news sobre el tema.

Las tecnologías también fueron una dimensión importante en el terreno educativo. Con la mayoría de las universidades y escuelas secundarias optando por continuar el dictado de clases a distancia, algunas aplicaciones se volvieron de público conocimiento. Zoom. Jitsi, Google Meet y Classroom, además de las palabras "clase virtual" y "campus" comenzaron a formar parte generalizada de la práctica educativa. Profesores que propusieron a los estudiantes tener clases sincrónicas mediante videollamadas masivas, donde la disputa entre Zoom y Jitsi tuvo un round sobre la privacidad de los datos y de la propia videollamada que podría ser filtradaiii. Incluso se conocieron casos de personas que ingresaron a las salas de 
videollamada sin formar parte del grupo. Este contexto permitió volver a pensar la educación ligada a las tecnologías, más allá de que las universidades mantienen hace años una actividad alrededor de carreras y cursos virtuales. Dimensión que también demostró la actualización de los docentes y la fortaleza de una profesión que salió a virtualizar las clases y asumir un rol social que esta vez le solicitaba que los estudiantes no perdieran meses de estudio. Por su parte, los estudiantes también pusieron lo suyo y se bancaron en algunos casos clases repletas de textos y con pocas explicaciones, como otras que buscaron hacer una transposición mimética de la presencialidad.

En algún momento del siglo $X X$ hubo quienes pensaron a las tecnologías como salvadoras de algunos de los problemas de la educación y como actualización y cercanía a las cotidianidades juveniles de los estudiantes. En momentos como estos donde la eventualidad hace necesario recurrir a tecnologías y saberes alrededor de ellas para clases virtuales, se revalorizan políticas públicas como el Programa Conectar Igualdad. Un derecho consagrado durante el gobierno de Cristina Fernández de Kirchner y destruido en una planificada retirada del estado. El Ministerio de Educación de la Nación en medidas inmediatas y pertinentes decidió reanudar la entrega de notebooks a estudiantes de escuelas secundarias, además de proponer el portal Seguimos Educando con contenidos educativos ${ }^{\text {iv }}$.

Por otra parte, en el terreno del entretenimiento, los escenarios tecnológicos vieron un crecimiento exponencial de su uso. Algunas aplicaciones hallaron terreno firme para tener repercusión masiva, como Tik Tok, que superó los dos mil millones de descargas y se convirtió en furor entre los más jóvenes ${ }^{v}$. Se trata de una red social donde los usos llevaron a que se publiquen mayormente videos breves de personas realizando humor mediante la mímica de audios o canciones conocidas. Por su parte, en Twitter se dieron unas dinámicas de entretenimiento que se denominaron "mundiales". Esto es elegir en formato de encuesta y entre 32 competidores (como en un mundial de fútbol) las más diversas (y en algunos casos disparatadas) opciones que se disputan un primer puesto: lugares de una ciudad, bebidas alcohólicas, series de televisión, universidades y profesores de tal o cual universidad, etc ${ }^{\mathrm{vi}}$. Mientras tanto, en Instagram explotaba el uso de una de sus opciones: el video en directo. Personas en aislamiento que transmitían (bajo la televisiva idea de broadcasting) y dialogaban con mirada a cámara con sus seguidores. El vivo de instagram permite sumar a otros a la 
charla y que los demás sean espectadores que pueden comentar en escrito. Esta posibilidad fue utilizada por famosos para dialogar con sus fanáticos, por músicos para realizar mini conciertos desde sus hogares y por ignotos para mostrar la intimidad de sus casas. Incluso el domingo 29 de marzo tuvo lugar el festival \#YoMeQuedoEnCasaFestival en el que durante varias horas participaron músicos de diferentes lugares del mundo. Como también algunos boliches y fiestas transmitieron música los fines de semana invitando a sus seguidores a que participen disfrutando como si estuvieran en la presencialidad, allí la cuenta de la Fiesta Bresh alcanzó 37 mil conectados comentando las canciones, donde no faltaron influencers y famosos.

En términos de entretenimiento también se vio una suba de casi 16 millones de suscripciones a la plataforma de video bajo demanda Netflix, al tiempo que algunas pantallas como HBO Go liberaron contenidos premium para ver durante el aislamiento vii. Estas decisiones tuvieron en cuenta que la gente comenzaba a modificar sus horarios de rutina durmiendo más tarde y consumiendo producciones culturales en todo momento. Atendiendo a ese contexto de uso, Netflix anunció que bajaría la calidad de sus contenidos para no sobrecargar el tráfico de internet. Mientras tanto los consumos piratas de música, audiovisual, textos y software crecían, la polémica no tardó en instalarse cuando un grupo de escritores, bajo el hashtag \#NoRegalenMisLibros se opuso a que sus obras se compartieran mediante archivos pdf en las redes sociales reabriendo el debate sobre el acceso a la cultura ${ }^{\text {viii. }}$

Finalmente, debemos hablar de sexting. Una práctica que en otros tiempos se denominó cibersexo o sexo virtual y que consiste en que dos personas mantengan una conversación mediada por tecnologías, con contenido sexual, enviarse audios, fotografías y videos (que en la actualidad de las redes se denominan como nudes), y que dado el aislamiento y la distancia debió masificarse hasta llegar a ser un tema tratado en medios de comunicación y por la opinión pública (Karrera y Garmendia, 2018). Incluso la práctica del sexting formó parte de una inédita propuesta gubernamental para pasar mejor el aislamiento.

El sexo virtual en cuarentena también tuvo como protagonista a páginas de audiovisual pornográfico como PornHub que dejó liberado su contenido premium ${ }^{\text {ix }}$. Mientras también se crearon grupos de Whatsapp y de Instagram para tener sexo virtual grupal. El 21 de marzo, la cuenta de Instagram PoliamorYMemes propuso a sus seguidores realizar un "mandala de nudes", esto es un chat grupal de Instagram en el cual compartir imágenes personales de 
calidad erótica con el resto de los participantes con el fin de que "todos llevemos una cuarentena cálida y entretenida". Estos grupos mantienen ciertas reglas de funcionamiento que se aceptan y resguardan con el propio honor. Buscar dos o más personas con quien se quiera compartir nudes, asegurarse que den su consentimiento para participar, establecer reglas claras, crear el chat grupal, que cada persona que ingrese debe enviar dos nudes y debe invitar a dos personas más y repetir hasta que el grupo se complete con 32 participantes como es el límite de los chats en la aplicación. Las reglas del juego fueron claras: lo que sucedía en el grupo se quedaba en el grupo, la prohibición de capturar la pantalla, no compartir fotografías de personas que no forman parte del grupo, no juzgar los cuerpos, todos los participantes debían tener privilegios de administrador, y con la obligación de compartir material de manera periódica y no solamente formar parte para ver.

Cada uno de los temas que mencionamos debería ser objeto de estudio de una profunda reflexión por separado y atendiendo a variables de análisis específicas. Estos escenarios de información, educación, entretenimiento y sexting son bastante parecidos a los que acostumbramos a transitar, aunque se dan maximizados en un contexto excepcional de pandemia. Un momento histórico que nos obligó a aislarnos, a modificar dinámicas laborales, de estudio y cotidianas. Allí es propicia la reflexión sobre nuestras prácticas más incorporadas con la comunicación y las tecnologías. Valorar instancias presenciales, dinamizar usos y apropiaciones tecnológicas y acrecentar la responsabilidad en el manejo de nuestra comunicación digital.

Alli el exceso de información, los datos cuantificables y las opiniones pueden causar los más contradictorios resultados, generar confianza o pánico. En ese sentido, las noticias falsas que forman parte del entramado político usual, en este contexto se masificaron para dividir a la opinión pública incluso ante la decisión de cuidar la salud pública como derecho humano.

En el contexto de aislamiento se pone también sobre la mesa la discusión sobre la pertinencia de la continuidad de las labores profesionales, estudiantiles y de entretenimiento, que como si no pasara nada deben seguir adelante a como dé lugar. En medio de conjeturas entre pesimistas y optimistas sobre cómo será el mundo luego-de-que-pase-esto, la situación pone 
una vez más en evidencia un sistema capitalista expresado tanto en el mercado y como en los signos, que no concibe la suspensión de sus actividades y que nos regala promociones, nos distingue, nos permite continuar con los deseos de futuro, mientras sigue maximizando ganancias con nuestras prácticas, nuestras subjetividades, nuestros temores, pánicos y esperanzas, aún en un excepcional estado de aislamiento social preventivo y obligatorio por causa de una pandemia de escala global que debe leerse tanto desde lo material como desde lo simbólico.

\section{Bibliografía}

Aparici, Roberto y García Marín, David (2019) "Historia de la mentira: más allá de Derrida”. En La posverdad. Una cartografía de los medios, las redes y la política. Barcelona: Gedisa.

Jenkins, Henry (2008) Convergence Culture. La cultura de la convergencia de los medios de comunicación. Buenos Aires: Paidós.

Karrera Iñaki y Garmendia Maialén (2018) "Sexting: qué sabemos y qué nos queda por aprender". En Entre selfies y whatsapps. Oportunidades y riesgos para la infancia y la adolescencia conectada. Barcelona: Gedisa.

Rincón, Omar (2005) "Culturas mediáticas”. En Narrativas mediáticas. Barcelona: Gedisa.

Silverstone, Roger (2004) ¿Por qué estudiar los medios?. Buenos Aires: Amorrortu.

\section{Notas}

\footnotetext{
i Aislamiento Social Preventivo y Obligatorio. Decreto 297/2020, disponible en: https://www.boletinoficial.gob.ar/detalleAviso/primera/227042/20200320 (del 19 al 31 de marzo, prorrogado por el decreto 325/2020).
} 
Decreto $355 / 2020$

https://www.boletinoficial.gob.ar/detalleAviso/primera/227694/20200411 (11 al 26 de abril).

Decreto 408/2020

https://www.boletinoficial.gob.ar/detalleAviso/primera/228261/20200426 (27 de abril al 10 de mayo).

ii “El Presidente y las infancias", en Página 12, 27/04/2020. Disponible en:

https://www.pagina12.com.ar/262456-el-presidente-y-las-infancias (Consultado el 02/05/2020).

iii “Los riesgos de Zoom y las ventajas de Jitsi”, en Página 12, 12/04/2020. Disponible en:

https://www.pagina12.com.ar/258659-los-riesgos-de-zoom-y-las-ventajas-de-jitsi (Consultado el 02/05/2020).

iv "Coronavirus: Netbooks para reducir la brecha digital durante la pandemia", en Página 12, 28/04/2020.

Disponible en: https://www.pagina12.com.ar/262515-coronavirus-netbooks-para-reducir-la-brechadigital-durante- (Consultado el 02/05/2020).

Seguimos Educando, Disponible en: https://www.educ.ar/noticias/etiqueta/seguimos-educando (Consultado el 02705/2020).

$\checkmark$ "Cuarentena: Tik Tok ya superó las 2.000 millones de descargas", en Infobae, 30/04/2020. Disponible en: https://www.infobae.com/america/tecno/2020/04/30/cuarentena-tik-tok-ya-supero-las-2000-millonesde-descargas/ (Consultado el 02/05/2020).

vi “““Mundiales” de Twitter: cómo funcionan y cuáles son los diez más populares de la cuarentena”, en VíaPaís, 27/04/2020. Disponible en:

https://viapais.com.ar/rumbos/1726137-mundiales-de-twitter-como-funcionan-y-cuales-son-los-diez-maspopulares-de-la-cuarentena/ (Consultado el 02/05/2020).

vii "Netflix suma casi 16 millones nuevos suscriptores en cuarentena", en Télam, 22/04/2020. Disponible en: https://www.telam.com.ar/notas/202004/454806-netflix-cuarentena-aislamiento-coronavirus.html (Consultado el 02/05/2020).

"HBO libera algunos contenidos durante la cuarentena", en Página 12, 10/04/2020. Disponible en: https://www.pagina12.com.ar/258627-hbo-libera-algunos-contenidos-durante-la-cuarentena (Consultado el 02/05/2020).

viii ““'No regalen mis libros”: polémica por una página que sube obras que tienen derechos de autor”, en Clarín, 30/04/2020. Disponible en: https://www.clarin.com/cultura/-regalen-libros-polemica-pagina-subelibros-derechos-autor_0_m2b3OXElj.html (Consultado el 02/05/2020). 
ix "Porno gratis en Argentina por el coronavirus: Pornhub libera sus contenidos en todo el mundo", en Clarín, 24/03/2020. Disponible en: https://www.clarin.com/internacional/porno-gratis-argentinacoronavirus-pornhub-libera-contenidos-mundo_0_jdmL1_6wa.html (Consultado el 02/05/2020). 